\title{
Pengaruh Suhu Tinggi terhadap Karakteristik Keramik Cordierite Berbasis Silika Sekam Padi
}

\author{
Simon Sembiring, ${ }^{*}$ Posman Manurung, dan Pulung Karo-Karo \\ Jurusan Fisika Bidang Material, Universitas Lampung \\ Jl. Prof. Dr. Sumantri Brojonegoro, Bandarlampung 35145
}

\begin{abstract}
Intisari
This study was carried out to investigate the effect of high temperature on the functional groups, microstructure and physical characteristics of cordierite ceramics obtained from an aqueous solution of magnesium nitrate hydrate $\left(\left(\mathrm{Mg}\left(\mathrm{NO}_{3}\right)_{2} \cdot 6.12 \mathrm{H}_{2} \mathrm{O}\right)\right)$, aluminium nitrate hydrate $\left(\mathrm{Al}\left(\mathrm{NO}_{3}\right)_{2} .9 .15 \mathrm{H}_{2} \mathrm{O}\right)$ and silica sols extracted from rice husk. The samples were sintered at temperature of $1000^{\circ} \mathrm{C}, 1200^{\circ} \mathrm{C}$ and $1400^{\circ} \mathrm{C}$. Functional groups and microstructural characteristics of cordierite ceramics were examined by FTIR and SEM, respectivelly. FTIR study shows that the absence of the vibration bands of $\mathrm{Na}-\mathrm{OH}, \mathrm{Si}-\mathrm{OH}, \mathrm{C}-\mathrm{O}, \mathrm{Si}-\mathrm{O}-\mathrm{Si}$ on the samples. However, the formation of cordierite structure was dominated on this high temperature. Microstructure results confirmed the presence of irregular morphology of the solid and compact phases. In addition, the densities, shrinkage and hardness of cordierite increase significantly with increasing temperature, but porosity decreases with increasing temperature.
\end{abstract}

KATA KUNCI: rice husk, cordierite, mikrostructure, sintering

\section{PENDAHULUAN}

Cordierite salah satu material dengan struktur silika yang bervariasi, diantaranya entatite, magnesium silicate, dengan cordierite memiliki kandungan silika paling tinggi dan stabil [1], yang secara luas telah diaplikasikan di berbagai industri seperti, industri gelas, industri keramik dan industri elektronik sebagai isolator panas dan listrik, karena memiliki kestabilan termal dan daya tahan terhadap zat kimia yang tinggi serta koefisien termal rendah [2]. Keramik cordierite dapat disintesis dari berbagai bahan baku silika mineral seperti fumed silika, kaolinite, TMOS (tetramethylortosilicate), maupun TEOS (tetraethylorthosilicate), melalui berbagai metode diantaranya, teknik reaksi padatan (solid-state reaction) [3, 4], teknik sol-gel [5, 6], teknik melting [7, 8].

Pada penelitian yang telah dilakukan terhadap karakteristik cordierite pada suhu rendah yakni $300-700^{\circ} \mathrm{C}$ dengan menggunakan silika sekam padi [9] menunjukkan bahwa karakteristik fungsionalitas cordierite terdiri dari $\mathrm{Si}-\mathrm{OH}, \mathrm{Si}-\mathrm{O}-\mathrm{Al}$, $\mathrm{Mg}-\mathrm{O}-\mathrm{Al}$, Na-OH, N-O, C-O dan $\mathrm{C}-\mathrm{H}$ pada suhu $300^{\circ} \mathrm{C}$ dan $500^{\circ} \mathrm{C}$, dan proses kristalisasi pembentukan cordierite melalui spinel $\mathrm{MgAlO}_{2}$ pada suhu sintering $700^{\circ} \mathrm{C}$. Sebagai tambahan, hasil analisis SEM/EDS menunjukkan bahwa mikrostruktur dengan pori dan kekerasan meningkat dengan meningkatnya suhu sintering dengan kehadiran komposisi elemen $\mathrm{Si}, \mathrm{Al}, \mathrm{Mg}$ dan O. Perubahan sifat fisis (shrinkage, porositas, densitas dan kekerasan mengalami perubahan yang signifikan pada suhu sintering $700^{\circ} \mathrm{C}$. Dari penelitian awal yang dilakukan, dapat disimpulkan bahwa proses kristalisasi diantaranya pemadatan (densification), pemben-

\footnotetext{
*E-MAIL: Simbiring@yahoo.com.au
}

tukan cordierite tergantung suhu sintering dan membutuhkan energi termal yang lebih tinggi untuk mengubah struktur. Berdasarkan latar belakang yang dipaparkan di atas, untuk melengkapi informasi pembentukan cordierite maka penelitian ini dilakukan dengan tujuan untuk mempelajari pengaruh temperatur tinggi terhadap karakteristik fungsionalitas, mikrostruktur dan fisis bahan keramik cordierite.

\section{METODE PENELITIAN}

Penelitian ini dilakukan di Laboratorium Fisika Material, Kimia Fisik, Jurusan Kimia Universitas Lampung dan di Pusat Penelitian Bahan BATAN Bandung. Dalam penelitian ini digunakan sekam padi yang diekstrak untuk mendapatkan silika sebagai bahan dasar dalam mensintesis cordierite dengan bahan kimia yang digunakan meliputi larutan $\mathrm{KOH} 5 \%, \mathrm{HCl}$ $10 \%$, magnesium nitrat hydrate $\left(\left(\mathrm{Mg}\left(\mathrm{NO}_{3}\right)_{2} \cdot 6 \cdot 12 \mathrm{H}_{2} \mathrm{O}\right)\right)$, aluminium nitrat hydrate $\left(\mathrm{Al}\left(\mathrm{NO}_{3}\right)_{2} \cdot 9.15 \mathrm{H}_{2} \mathrm{O}\right)$, Merck $\mathrm{KgaA}$ 64271 (Darmstadt Germany), $\mathrm{NH}_{3}$, aquades, etanol, metanol, indikator $\mathrm{pH}$. Peralatan yang digunakan adalah furnace merk Nobertherm, timbangan analitik listrik (Model GR-120, Japan), dan Spectometer Infrared (Shimadzu, FTIR, 8201, PC, Japan), dan Scanning Electron Microcopy (SEM) Philips XL-30, serta alat pendukung lain seperti plate panas pengaduk (stirring-hot plate), ayakan $125 \mu \mathrm{m}$ (Merck Endecotts Limited London SW 3TZ England), cawan porselen, pipet, mortar dan pastle serta alat press hidrolik (Graseby Specac). Untuk mendapatkan silika sebagai bahan baku cordierite, sekam padi diekstrak dengan mengacu pada prosedur yang telah dilakukan sebelumnya [10]. Kemudian, mencampurkan bahan dasar magnesium nitrat hydrate $\left(\mathrm{Mg}\left(\mathrm{NO}_{3}\right)_{2} \cdot 6.12 \mathrm{H}_{2} \mathrm{O}\right)$, aluminium nitrat hydrate $\left(\mathrm{Al}\left(\mathrm{NO}_{3}\right)_{2} \cdot 9.15 \mathrm{H}_{2} \mathrm{O}\right.$, dan silika sol hasil ekstraksi mengacu pada prosedur yang sudah dilakukan $[9,11]$ yakni diaduk dengan magnetic stirrer dengan meng- 


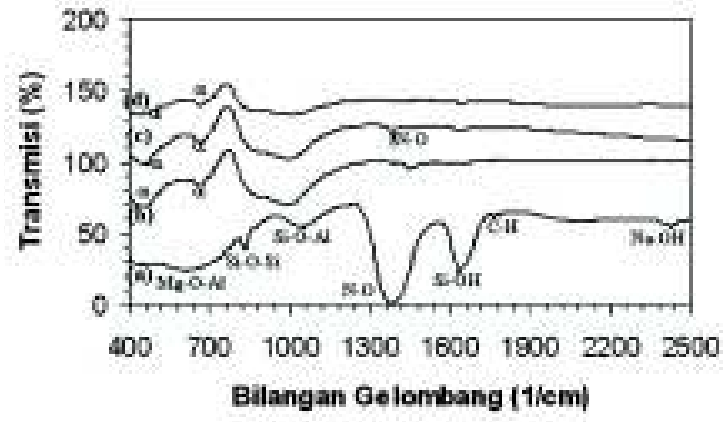

Gambar 1: Spektrum FTIR cordierite hasil sintesis dari silika sekam padi (a) tanpa Sintering, (b) $1000^{\circ} \mathrm{C}$, (c) $1200^{\circ} \mathrm{C}$, dan (d) $1400^{\circ} \mathrm{C}: \alpha$ = Cordierite

gunakan mediator air bebas ion dengan penambahan $\mathrm{NH}_{3}$ secara bertahap, hingga sol berubah menjadi gel yang jernih putih dan transparan. Selanjutnya, dilakukan pengeringan pada suhu $110^{\circ} \mathrm{C}$ selama 8 jam untuk mendapatkan gel dalam bentuk serbuk dan digerus dengan ukuran butir $125 \mu \mathrm{m}$ lalu disintering pada suhu $1000^{\circ} \mathrm{C}, 1200^{\circ} \mathrm{C}$, dan $1400^{\circ} \mathrm{C}$ dengan heating rate $3^{\circ} / \mathrm{min}$ selama 2 jam.

\section{HASIL DAN PEMBAHASAN}

Hasil analisis FTIR disajikan dalam Gambar 1 yang mengindikasikan adanya beberapa gugus fungsi yang dimiliki oleh silika dan cordierite.

Gambar 1(a) menunjukkan hasil analisis FTIR tanpa sintering, dengan puncak vibrasi utama pada bilangan gelombang, $1631,7 \mathrm{~cm}^{-1}, 1384,8 \mathrm{~cm}^{-1}$, dan $1049,2 \mathrm{~cm}^{-1}$, yakni gugus fungsi $\mathrm{Si}-\mathrm{OH}$ yang terjadi akibat interaksi air dengan silika $[12,13]$, gugus yang khas untuk vibrasi $\mathrm{NO}^{-3}$ muncul dari bahan yang digunakan pada penelitian ini, yang didukung oleh penelitian sebelumnya dengan mengekstrak silika dengan menggunakan $\mathrm{HNO}_{3}$ [14], dan gugus fungsi Si-O-Al yang terjadi akibat deformasi gugus $\mathrm{Si}-\mathrm{O}-\mathrm{Si}$ [15], dan berinteraksi dengan $\mathrm{Al}$ membentuk gugus $\mathrm{AlO}_{6}$ octahedral [16, 17]. Selain itu, puncak lain yang cukup signifikan untuk sampel tanpa sintering terdapat pada bilangan gelombang $2426,3 \mathrm{~cm}^{-1}, 1789,8 \mathrm{~cm}^{-1}, 1762,8 \mathrm{~cm}^{-1}$, masing masing mengindikasikan interaksi gugus $\mathrm{OH}$ dengan $\mathrm{NaOH}$ di dalam cellulosa dan ikatan $\mathrm{C}-\mathrm{O}$ dengan sellulosa yang terlarut dan diserap silika [13].

Seiring dengan kenaikan suhu sintering yakni $1000^{\circ} \mathrm{C}$, $1200^{\circ} \mathrm{C}$, dan $1400^{\circ} \mathrm{C}$ (Gambar 1 (b), (c) dan (d)) menunjukkan perbedaan gugus fungsi yang cukup signifikan dengan tanpa sintering (Gambar 1a), yakni tidak teridentifikasinya gugus fungsi $\mathrm{Na}-\mathrm{OH}$, Si-OH, C-O, Si-O-Si, namun puncak khas untuk vibrasi $\mathrm{NO}^{-3}$, muncul pada sampel sintering $1200^{\circ} \mathrm{C}$. Hasil ini mengindikasikan bahwa mulai suhu sintering $1000^{\circ} \mathrm{C}$ terjadi proses kristallisasi yang mengakibatkan terjadinya pemadatan (densification). Proses kristallisasi dapat dilihat semakin meningkat puncak vibrasi pada bilangan gelombang $987,5 \mathrm{~cm}^{-1}, 883,3 \mathrm{~cm}^{-1}, 659,6 \mathrm{~cm}^{-1}, 617,2$

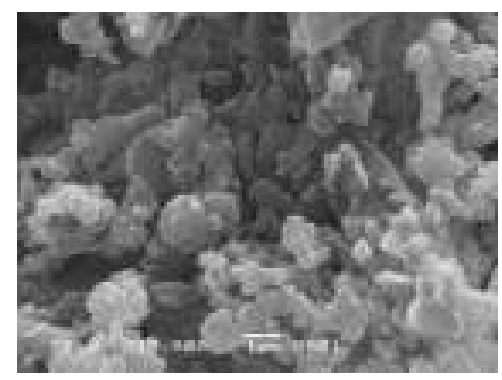

(a)

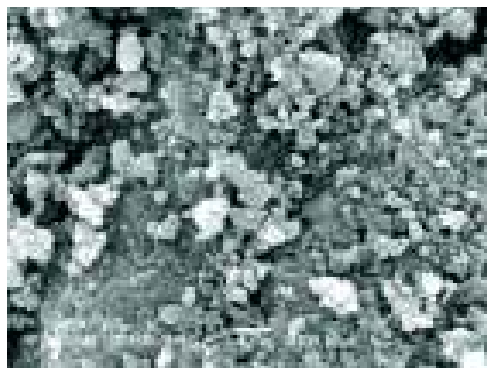

(b)

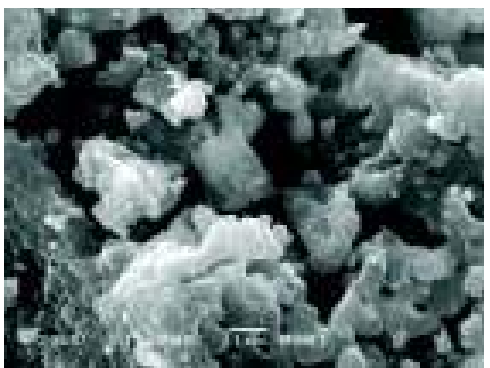

(c)

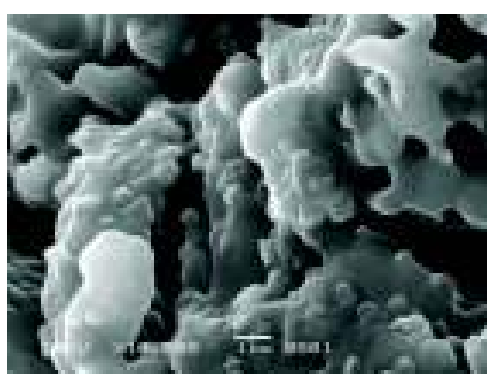

(d)

Gambar 2: Analisis SEM sampel cordierite hasil sintesis dari silika sekam padi (a) tanpa sintering, (b) $1000^{\circ} \mathrm{C}$, (c) $1200^{\circ} \mathrm{C}$ dan (d) $1400^{\circ} \mathrm{C}$

$\mathrm{cm}^{-1}, 466,7 \mathrm{~cm}^{-1}$, dan $439 \mathrm{~cm}^{-1}$, yang menunjukkan karakteristik cordierite, akibat interaksi $\mathrm{Mg}$ dan $\mathrm{Al}$ dengan oksigen (Gambar 1 (a)) dengan bilangan gelombang 825,2 $\mathrm{cm}^{-1}$ dan $447,5 \mathrm{~cm}^{-1}$ bereaksi dengan $\mathrm{Si}-\mathrm{O}-\mathrm{Si}$, yang sesuai dengan penelitian sebelumnya $[12,18]$ yang menyimpulkan bahwa pembentukan cordierite diikuti dengan $\mathrm{MgAlO}_{2}$ spinel.

Karakteristik mikrostruktur sampel cordierite tanpa sintering dan yang disintering pada suhu $1000^{\circ} \mathrm{C}, 1200^{\circ} \mathrm{C}$ dan 


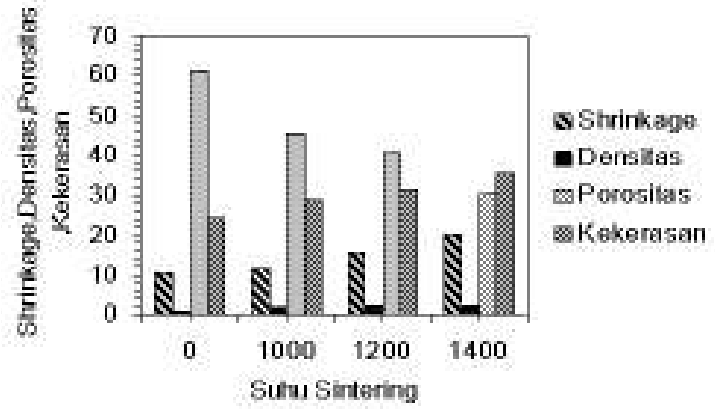

Gambar 3: Pengaruh sintering terhadap sifat fisis (shrinkage, porositas, densitas dan kekerasan) sampel cordierite hasil dari ekstraksi silika sekam padi.

$1400^{\circ} \mathrm{C}$ disajikan dalam Gambar 2, sedangkan karakteristik fisis (shrinkage, densitas, porositas dan kekerasan) akibat perlakuan sintering disajikan pada Gambar 3. Morfologi permukaan (Gambar 2(a)) kelihatan tidak homogen dan memiliki pori, terdiri dari gumpalan dan bulat (cluster and globular) membentuk butiran-butiran kecil (granular) dengan ukuran dan bentuk partikel yang berbeda, dan tersebar secara tidak merata pada permukaan. Perbedaan ukuran dan bentuk partikel menunjukkan bahwa mikrostruktur permukaan sampel cordierite berbentuk amorph, terdiri dari beberapa komponen yang berikatan dengan silika membentuk gugus, seperti yang ditunjukkan hasil analisis FTIR (Gambar 1(a)), sehingga memiliki jumlah pori (porositas) yang besar (Gambar 3).

Selanjutnya permukaan sampel cordierite pada suhu sintering $1000^{\circ} \mathrm{C}$ kelihatan membentuk cluster dan butiran yang lebih kecil, padat dan menyatu (solid and compact), sehingga jumlah pori (porositas) mengalami penurunan (Gambar 3), sementara permukaan sampel cordierite pada suhu sintering $1200^{\circ} \mathrm{C}$ kelihatan membentuk cluster yang lebih besar, padat dan menyatu (solid and compact) dengan luas permukaan semakin besar, sehingga jumlah pori (porositas) mengalami penurunan (Gambar 3), dan diikuti peningkatan densitas, shrinkage maupun kekerasan karena mencapai pembentukan kristal cordierite yang ditunjukan hasil analisis FTIR (Gambar 1(c)). Pada suhu sintering $1400^{\circ} \mathrm{C}$ (Gambar 2 (d)), morfologi permukaan kelihatan semakin solid dan compact, dengan luas permukaan meningkat, ukuran dan bentuk butiran terdistribusi merata (homogen). Hasil ini mengindikasikan bahwa proses kristallisasi pembentukan cordierite, dengan penurunan porositas diikuti dengan peningkatan shrinkage dan kekerasan yang cukup signifikan (Gambar 3).

\section{SIMPULAN DAN SARAN}

Dari serangkaian percobaan yang dilakukan pada penelitian ini, diperoleh beberapa kesimpulan berkaitan dengan karakteristik keramik cordierite berbasis silika sekam padi pada suhu tinggi yakni (1) karakteristik fungsionalitas pada suhu tinggi menunjukkan tidak teridentifikasi komponen Na$\mathrm{OH}, \mathrm{Si}-\mathrm{OH}, \mathrm{C}-\mathrm{O}, \mathrm{Si}-\mathrm{O}-\mathrm{Si}$, (2) proses kristallisasi didominasi oleh pembentukan cordierite dan perubahan karakteristik fisis (porositas, densitas dan kekerasan) pada suhu tinggi mengalami perubahan yang cukup signifikan, (3) karakteristik mikrostruktur menunjukkan terbentuknya kristal keramik cordierite dengan membentuk gumpalan (cluster).

Untuk mendapatkan hasil yang lebih rinci disarankan dilakukan karakterisasi pada suhu $1500^{\circ} \mathrm{C}$ dengan menggunakan XRD dan DTA untuk mendapatkan struktur dan sifat termal dan kekerasan maximum. Penelitian ini merupakan lanjutan dari serangkaian penelitian yang kami lakukan di Fisika Bidang Material FMIPA Universitas Lampung.

\section{Ucapan Terima Kasih}

Penelitian ini dapat dilakukan berkat bantuan Dana Direktorat Penelitian Dan Pengembangan Kepada Masyarakat DIKTI Dengan Surat Kontrak NO 010/SP2H/DP2M/III/2008
[1] Kingrey, W.D, Bowen, H.H, Uhlmann, D.R, Introduction to Ceramics $\left(2^{\text {nd }}\right.$, Eddition, Jhon Wiley \& Sons, 1976).

[2] Goncalves, M.R.F, Bergmann, C.P, Thermal Insulator made with Cordierite: Production and Correlation between Properties and Microstructure (Contruction and Building Materials, 2006).

[3] Kurama, S and Kurama, H, The Reaction Kinetics of Rice Husk Based Cordierite Ceramic (Ceramic International, 1 - 4, 2006).

[4] Kurama, S and Ozel, N., Synthesis and Sintering of Cordierite at Low Temperature from Kaolinite and Magnesium Hydroxide, Key Engineering Materials, 92 - 928 (2004).

[5] Douy, A., Organics Gels in The Preparation of Silicate Powders Example of Mullite and Cordierite, In Chemical Processing of Advanced Materials, New York, pp. 585 - 594, 1992.

[6] Naskar, M.K and Chatterjee, Materials Letters, 59, 998-1003 (2005).

[7] Rudolph, T; Pannhorst, W; Petzow, G.,Journal Non-Crystalline Solid, 155, 273-281 (1993).
[8] Amista, P; Cesari, M; Montenero, A; Gnappi, G; Lan, L., Journal Non-Crystalline Solid, 192, 529-533 (1995).

[9] Sembiring, S, Karakteristik Keramik Cordierite Berbasis Silika Sekam Padi Pada Temperatur Rendah (Low Temperature), to be submitted in Journal Saintika, Universitas Medan (UNIMED) (2008).

[10] Sembiring, S dan Karo-Karo, K, Pengaruh suhu Sintering Terhadap Karakteristik Termal dan Mikrostruktur Silika Sekam Padi, jurnal Sains dan Teknologi, Mipa Unila (2007).

[11] Triyanti, S, Pengaruh Suhu Sintering Terhadap Fungsionalitas dan Karakteristik Thermal Bahan Keramik Cordierite Berbasis Silika Sekam Padi, Thesis Universitas Lampung, 2008.

[12] Adam, F, Kandasamy, Balakrishnan, S., J. Coloid and Interface Science, 304, 137-143 (2006).

[13] Ndazi, B.S, Karlsoon, S, Tesha,J.V, Nyahumwa, C.W, Chemical and Physical Modification of Rice Husks for Use as Composite panels, Composite Part A: Applied Science and Manufacturing, 
p1-11 (2006).

[14] Ebsworth, E.A.V, Rankin, D.W.H, Cradock, S,Structural Methods in Organic Chemistry (Second ed, Blackwell Scientific Publication Oxford United Kingdom, p222, 1991).

[15] Daifullah, A.A.M; Girgis, B.S and Gad, H.M.H, Materials Letters, 57, 1723-1731 (2003).

[16] Chatterjee, M and Naskar M.K., Ceramic International, 32,
623-632 (2006).

[17] Naskar, M.K dan Chatterjjee, M., Journal of The EuropeanCeramic Society, 24, 3499-3507 (2004).

[18] Petrovic, R, Janaclovic, D, Bozovic, B, Zec, S and Gvozdenovic, L.K, Journal Sebian Chemical Society, 66(3), 335-343 (2001). 